Document downloaded from:

http://hdl.handle.net/10251/109806

This paper must be cited as:

Diego-Mas, JA.; Alcaide Marzal, J.; Poveda Bautista, R. (2017). Errors Using Observational Methods for Ergonomics Assessment in Real Practice. Human Factors The Journal of the Human Factors and Ergonomics Society. 59(8):1173-1187. doi:10.1177/0018720817723496

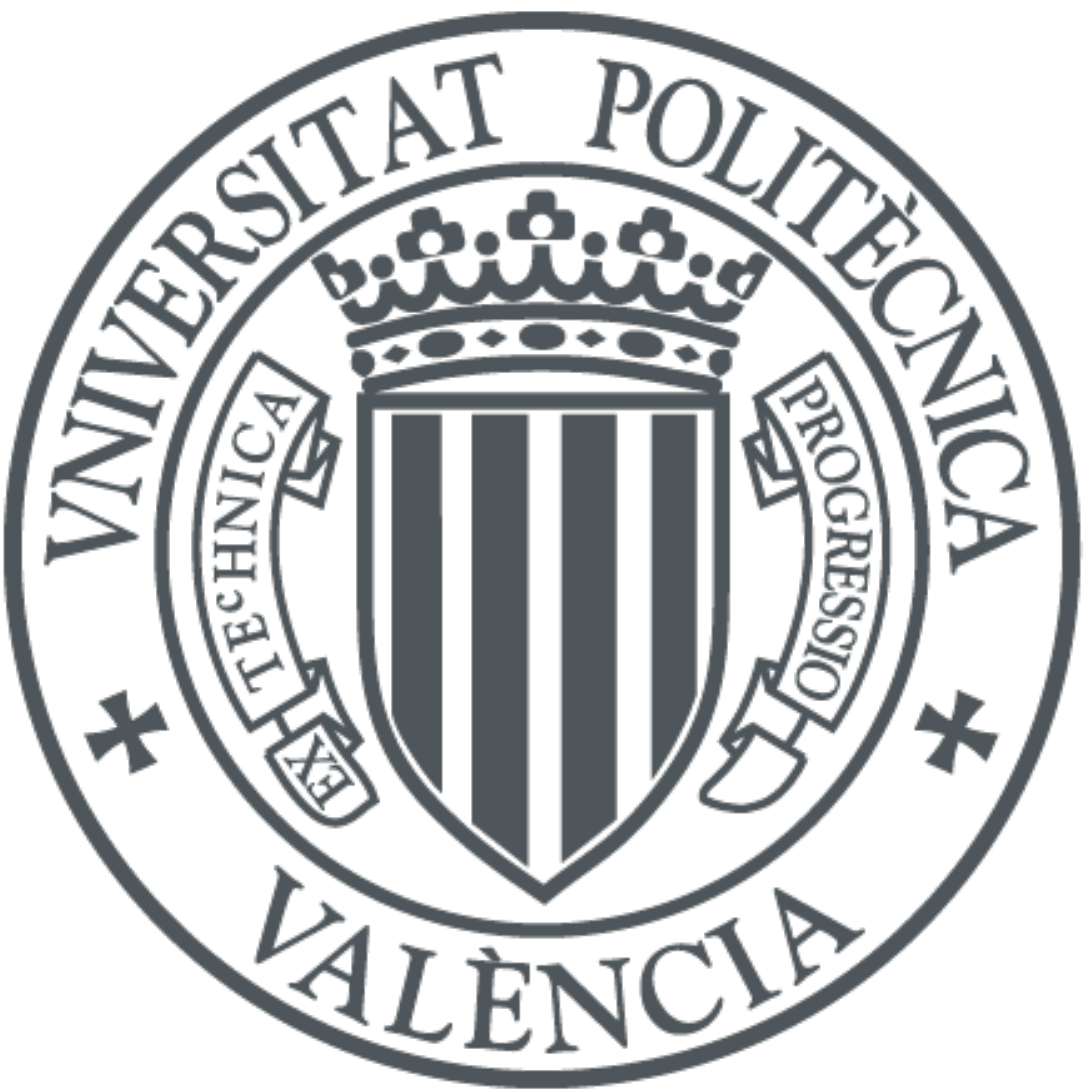

The final publication is available at

https://doi.org/10.1177/0018720817723496

Copyright SAGE Publications

Additional Information 
HUMAN FACTORS

Vol. XX, No. X, Month XXXX, pp. 1-15

DOI: $10.1177 / 0018720817723496$

\section{Author copy of: \\ Errors using observational methods for ergonomics assessment in real practice}

Jose-Antonio Diego-Mas $^{\mathrm{a}^{*}}$, Rocio Poveda-Bautista ${ }^{\mathrm{b}}$ and Jorge Alcaide-Marzal
${ }^{a}$ I3B, Institute for Research and Innovation in Bioengineering, Universitat Politècnica de València, Camino de Vera s/n, 46022 Valencia, Spain.

${ }^{b}$ INGENIO [CSIC-UPV], Universitat Politècnica de València, Camino de Vera s/n, 46022 Valencia, Spain.

* Corresponding author. Tel.:+34 963877000.

E-mail address: jodiemas@dpi.upv.es (J.A. Diego-Mas)

PRÉCIS/SHORT ABSTRACT: 442 musculoskeletal disorder risk assessments of actual jobs carried out by 290 professionals from 20 countries were analyzed to determine their reliability. Approximately one out of three assessments conducted by practitioners in actual work situations does not adequately evaluate the level of potential work-related musculoskeletal disorder risks.

Running head: Errors using observational methods.

Manuscript type: Research Article.

Word count of text: 4179

Acknowledgments: This work was supported by the Programa estatal de investigación, desarrollo e innovación orientada a los retos de la sociedad of the Government of Spain under Grant DPI2016-79042R. 


\section{ABSTRACT}

Objective: The degree in which practitioners use the observational methods for musculoskeletal disorder risks assessment correctly was evaluated.

Background: Ergonomics assessment is a key issue for the prevention and reduction of work-related musculoskeletal disorders in workplaces. Observational assessment methods appear to be better matched to the needs of practitioners than direct measurement methods, and for this reason, they are the most widely used techniques in real work situations. Despite the simplicity of observational methods, those responsible for assessing risks using these technics should have some experience and know-how in order to be able to use them correctly.

Methods: 442 risk assessments of actual jobs carried out by 290 professionals from 20 countries were analyzed to determine their reliability.

Results: The results show that approximately $30 \%$ of the assessments performed by practitioners had errors. In $13 \%$ of the assessments the errors were severe and completely invalidated the results of the evaluation.

Conclusion: Despite the simplicity of observational method, approximately one out of three assessments conducted by practitioners in actual work situations does not adequately evaluate the level of potential musculoskeletal disorder risks.

Application: This study reveals a problem that suggests that a greater effort is needed to ensure that practitioners possess better knowledge of the techniques used to assess work-related musculoskeletal disorder risks, and that laws and regulations should be stricter as regards qualifications and skills required by professionals.

KEYWORDS: job risk assessment; industrial/workplace ergonomics; human error analysis; measures; physical work 


\section{Introduction}

One of the objectives of occupational ergonomics is to care for workers' health avoiding their exposure to risks factors for musculoskeletal disorders. Achieving this objective reduces work-related physical or psychological disorders. The ergonomics assessment of work places is a key issue for preventing or reducing ergonomics risk factors. In this sense, ergonomics assessment methods are the tools for acquiring relevant and reliable evidence on which to base recommendations for changes to preserve workers' health. Increasingly, experts and researchers are developing new and improved assessment methods to be used by practitioners in real work environments.

Different criteria can be used to classify the methods to assess risk factors for musculoskeletal disorders (MSDs). For example, the width of the field of application, the complexity of collecting the data required, how much invasive the measurement technique is or the qualification of the practitioner required to apply the method correctly (Beek \& Frings-Dresen, 1998; Li \& Buckle, 1999; Malchaire, 2011; Wells, Norman, Neumann, \& Andrews, 1997). Direct measurement methods use sensors attached to the worker for the measurement of certain variables. Although these methods collect accurate data, they are invasive, require resources to cover the costs of maintenance and substantial initial investment for purchasing the equipment (Chiasson, Imbeau, Aubry, \& Delisle, 2012). On the other hand, the recruitment of highly qualified personnel to ensure the efficient operation of the equipment is needed (David, 2005; Trask \& Mathiassen, 2012). Researchers prefer to work with direct methods; however, these methods are not suitable for use in real work situations (Li \& Buckle, 1999; Roetenberg, Baten, \& Veltink, 2007). Observational methods (OMs) are based on direct observation of workers while performing their tasks. The practitioners collect the necessary data while observing the work carried out by the worker. After that, they use tables or equations to measure the risks related to ergonomics aspects of the tasks developed. OMs are usually easy to use, applicable to a wide variety of work situations at a comparatively lower cost and suitable for a large number of workers. For these reasons, OMs seem to be better adapted to the needs of practitioners who usually have limited resources and time and need techniques that allow them to set the priorities for intervention (David, 2005; Genaidy et al., 1994; Bao et al., 2009).

Despite the user-friendliness and simplicity of OMs over direct measurement methods, a certain level of experience and knowledge for their proper use is needed (OHSCO, 2008). For example, it is 
necessary to know what risk factor is being assessed and the particular conditions of the task under analysis for the correct selection of the most suitable assessment method. Moreover, knowledge about the degree of accuracy and reliability of the selected method and ability to correctly interpret the results are needed. Previous studies, workshops and discussions with practitioners (Buckle \& Li, 1996; David, 2005; David, Woods, Li, \& Buckle, 2008; Diego-Mas, Poveda-Bautista, \& Garzon-Leal, 2015; Li \& Buckle, 1999, 2000; Malchaire, 2011) led to the identification of the most important issues that need to be addressed for the correct operation of OMs. Training level and skills for applying these techniques, and difficulties finding reliable information about OMs, were some of the most important issues found. Although the knowledge and skills required differ depending on the method used (Takala et al., 2010), many countries current regulations do not guarantee that practitioners have the necessary qualifications to properly apply OMs. For example, the legislation of many European and American countries does not demand of companies that people responsible for carrying out risk assessments have specific training or qualifications. In some cases, the only requirement is to possess very basic training.

Therefore, in many cases the practitioners do not have the necessary training recommended for the correct use of ergonomics analysis tools or to correctly interpret the results obtained from their use. In Diego-Mas et al. (2015) 267 practitioners from companies with more than 10 employees who regularly conduct ergonomics assessments were interviewed. About $81.56 \%$ indicated that they had official qualifications or certifications enabling them to carry out tasks relating to ergonomics and occupational risk prevention in their companies; whereas $18.44 \%$ responded that they had no such certification. When asked whether they considered that they had enough training in ergonomics risk assessment to carry out their tasks appropriately, 59.84\% responded affirmatively, whereas $40.16 \%$ did not believe that they had enough training. In many cases, practitioners solve these problems through self-training and searching for the necessary information. However, another problem detected is that finding original or reliable information on a particular method can be difficult. Practitioners may lack the means required to access these resources. Therefore, practitioners obtain the information from other sources that provide incomplete or incorrect data. This problem is especially important for practitioners who do not speak English because the sources of the original information are usually written in English. 
The aforementioned studies indicate that, on the one hand, OMs are the most commonly used techniques to conduct ergonomics assessments by practitioners, but on the other hand, the level of training of practitioners in ergonomics may be insufficient to correctly apply the OMs. Therefore, to what extent can the lack of training of practitioners be the cause of unreliable conclusions when they use OMs to assess the risk of work related MSDs? The main objective of this work is to determine if assessments of MSDs risk factors conducted in companies using OMs are performed correctly or, conversely, the lack of specialized training or experience of practitioners may result in unreliable assessments. Knowing if OMs are correctly used in actual practice is important because these techniques are the first and most common tools to prevent the workers being exposed to risk factors for musculoskeletal disorders.

In the present work, the application process and the results of 442 ergonomics assessments of real workplaces were reviewed looking for errors. There are many MSDs risk factors and many OMs to assess them; therefore, it is very difficult to include all of them in a single study. Our work was focused on physical risk factors and associated OMs. To select them we followed the results found in Diego-Mas et al., 2015 about the OMs most commonly used in real practice.

\section{Methods}

Developing this study required ergonomics assessments of actual workplaces performed by practitioners. The ergonomics assessment reports were obtained using the website Ergonautas. Ergonautas is a web platform (http://www.ergonautas.upv.es) managed by the team who carried out this research. It mainly aims to provide online information and software in the Spanish language for applying tools and techniques commonly used for the ergonomics assessment of workplaces. When this work was performed, the platform had over 105,000 registered users from 60 different countries. About 8,000 of them had a professional user registration. Professional users pay for the registry and have access to advanced tools and online software, while the standard registration is free and provides limited access. Upon registration, professional users should complete a personal profile form in which information about their tasks, qualifications and companies is collected. 


\subsection{Selection of practitioners}

The web platform database was used to analyze the profiles of the registered professionals. Professionals who had not logged into the web platform in the past 6 months were excluded. Finally, a list of 1624 users who were registered as professionals from companies with more than 10 employees, and who had carried out ergonomics assessments using the platform software was obtained.

An email was sent to the candidates containing information regarding the study and instructions on how to participate. By agreeing to participate in the study, practitioners gave permission to store their ergonomics assessment reports on the platform server, and accepted to provide additional information and answer any further questions when required by the research team. Confidentiality of the personal information and the name of the companies involved in the study was granted. Participants in the study were rewarded with a free renewal of their registrations on the web platform. Responses were obtained from 645 professionals. 92 respondents were excluded because their profiles or jobs were different to those stored in the web platform due to recent changes. Finally, a list of 553 participants was obtained.

\subsection{Selection of observational assessment methods}

The observational assessment techniques used in this work were selected based on the results of the research conducted in Diego-Mas et al. (2015). The selected methods were as follows: National Institute for Occupational Safety and Health lifting equation (NIOSH) (Waters, Putz-Anderson, Garg, \& Fine, 1993); Snook and Ciriello tables of Maximum Acceptable Weights and Forces (Snook \& Ciriello, 1991); Rapid Entire Body Assessment (REBA) (Hignett \& McAtamney, 2000); Rapid Upper Limb Assessment (RULA) (McAtamney \& Corlett, 1993); Owako Working Posture Assessment System for posture assessment (OWAS) (Karhu, Kansi, \& Kourinka, 1977); Job Strain Index (JSI) (Moore \& Garg, 1995); Occupational Repetitive Action (OCRA) (Occhipinti, 1998); OCRA Checklist for repetitive movements assessment (Colombini, Occhipinti, Cairoli, \& Barracco, 2000); Laboratoire d'economie et de sociologie du travail (LEST) (Guelaud, Beauchesne, Gautrat, \& Roustang, 1977) and Chaffin Biomechanical Model (BiomechEEC, a computerized biomechanical model based on the proposal in Chaffin (1969)). 


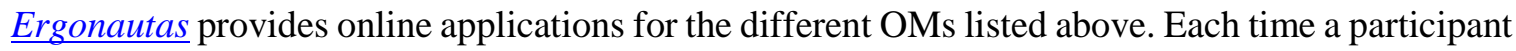
in the study completed an ergonomics assessment form with these applications, the record of accesses was updated and the assessment data was stored on the server.

\subsection{Study development}

The review team consisted of the authors of this work and ten ergonomics professionals. All of them had long experience with MSDs prevention and observational assessment techniques. The process began with several meetings in which the review team discussed the most convenient revision process and the classification of errors. The team determined how to analyze the ergonomics assessments conducted by practitioners looking for possible errors. Three categories of errors were identified, namely: Severe Errors, Moderate Errors and Application Errors.

Severe errors are conceptual errors that completely invalidate assessment reliability. This kind of errors indicates that the practitioner does not know how to use the method or applies it inappropriately. Examples of errors that fall into this category are using a method for assessing a risk factor for which it was not designed (for example, using the NIOSH lifting equation to assess worker postures) or improperly applying the method (for example, mixing data from both sides of the body to apply the RULA method). Moderate errors are errors that cause estimating the ergonomics risk incorrectly. In this case, the selection of the assessment method is appropriate and the task being assessed fulfils the required specifications, but the misapplication of the tool results in an improper assessment of the risk (e.g. errors in working posture coding from visual observations when using OWAS). Finally, Application errors are specific errors due to carelessness and not to lack of knowledge or training (e.g. errors in calculations or data typing errors using the software).

When one participant completed an ergonomics assessment form on the web platform, all data was stored in the server and the assessment was analyzed by one member of the review team. The assessment form comprises the numerical data required for the calculations, the images, observations and descriptions made by the professional. Additionally, when the reviewer considered that more information was needed to clarify some specific aspect of the assessment, he contacted the practitioner asking for additional information, such as images or further details about the way the evaluation was performed. When an error 
was identified in the assessment form, the reviewer decided whether it was classified as a severe, moderate or application error. In many cases, the reviewer contacted the practitioner again to know whether the error was due to lack of knowledge or if it was a punctual mistake. If the error found was considered to be severe, the reviewer coded the assessment as "with severe errors" and did not go on with the analysis process. When a moderate or application error was detected, the reviewer analyzed the assessment form comprehensively for the identification of more errors. After the revision, if moderate and application errors were detected in an assessment form, it was classified as "with moderate errors". If only minor errors were detected then the form was recorded as "with application errors”. If no errors were detected the form was coded as "without errors". In a second revision stage, each reviewer in charge showed the errors found in their revised assessments to the review team. If errors were found in the assessment, the team analyzed them and confirmed the degree of severity assigned. If no errors were detected in an assessment, it was revised by the team looking for undetected errors.

\subsection{Data analysis}

A descriptive statistical analysis was carried out on the errors detected in the 442 ergonomics assessments revised. A secondary descriptive statistical analysis was performed on the demographic data of the practitioners.

\section{Results}

Ergonomics assessments were received from 317 practitioners. Given that the number of practitioners invited to take part in this study was 553, the response rate was approximately 57.3\%. Each participant sent between 1 and 6 ergonomics assessments, finally receiving 474 assessments. The first ergonomics assessment was revised in July 2013 and the last one in September 2015.

For a given OM to be included in the study, at least 15 assessments should have been received from practitioners using that OM. 32 assessments were eliminated from the study because the OM used was not implemented in at least 15 forms. Therefore, 442 assessments were analyzed and 290 practitioners remained in the process. Figure 1 shows the demographic and professional profile of these practitioners, and Table 1 presents the distribution by country and the distribution of participants by number of assessments submitted 
for review. No significant correlations were found amongst years of experience, age, sex, or country and the number of errors in the assessments performed.

Figure 1. Gender, age and years of experience of the participants in the survey

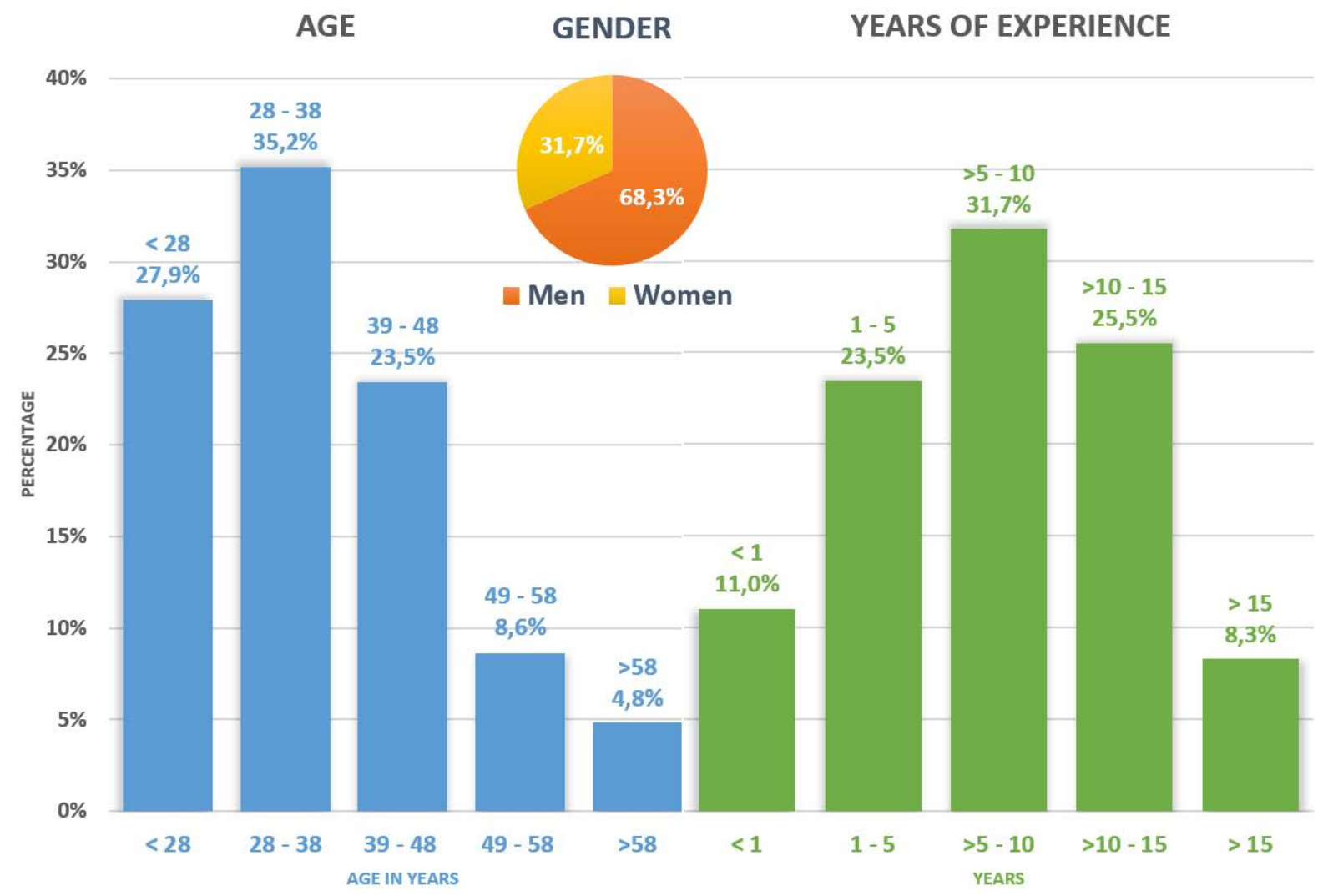

Table 1. Participants and assessments by country and number of assessments by participant.

\begin{tabular}{|c|c|c|c|c|c|c|c|c|}
\hline \multirow{3}{*}{ Country } & \multirow{3}{*}{ Total } & \multicolumn{6}{|c|}{ Participants } & \multirow{3}{*}{ Assessments } \\
\hline & & \multicolumn{6}{|c|}{ Number of assessments sent for review } & \\
\hline & & 1 & 2 & 3 & 4 & 5 & 6 & \\
\hline Spain & $\begin{array}{c}103 \\
35.5 \%\end{array}$ & 78 & 12 & 8 & 4 & 1 & 0 & $\begin{array}{c}147 \\
33.3 \%\end{array}$ \\
\hline Colombia & $\begin{array}{c}44 \\
15.2 \%\end{array}$ & 32 & 7 & 3 & 1 & 0 & 1 & $\begin{array}{c}65 \\
14.7 \%\end{array}$ \\
\hline Mexico & $\begin{array}{c}36 \\
12.4 \%\end{array}$ & 24 & 6 & 3 & 2 & 1 & 0 & $\begin{array}{c}58 \\
13.1 \%\end{array}$ \\
\hline Chile & $\begin{array}{c}22 \\
7.6 \%\end{array}$ & 15 & 5 & 2 & 0 & 0 & 0 & $\begin{array}{c}31 \\
7.0 \%\end{array}$ \\
\hline Argentina & $\begin{array}{c}17 \\
5.9 \%\end{array}$ & 12 & 4 & 1 & 0 & 0 & 0 & $\begin{array}{c}23 \\
5.2 \%\end{array}$ \\
\hline Venezuela & $\begin{array}{c}16 \\
5.5 \%\end{array}$ & 10 & 4 & 1 & 0 & 0 & 1 & $\begin{array}{c}27 \\
6.1 \%\end{array}$ \\
\hline U.S.A & $\begin{array}{c}10 \\
3.4 \%\end{array}$ & 6 & 3 & 0 & 1 & 0 & 0 & $\begin{array}{c}16 \\
3.6 \%\end{array}$ \\
\hline Peru & $\begin{array}{c}9 \\
3.1 \%\end{array}$ & 5 & 2 & 0 & 1 & 1 & 0 & $\begin{array}{c}18 \\
4.1 \%\end{array}$ \\
\hline Ecuador & 8 & 6 & 2 & 0 & 0 & 0 & 0 & 10 \\
\hline
\end{tabular}




\begin{tabular}{|c|c|c|c|c|c|c|c|c|}
\hline & $2.8 \%$ & & & & & & & $2.3 \%$ \\
\hline Costa Rica & $\begin{array}{c}4 \\
1.4 \%\end{array}$ & 3 & 1 & 0 & 0 & 0 & 0 & $\begin{array}{c}5 \\
1.1 \%\end{array}$ \\
\hline Guatemala & $\begin{array}{c}2 \\
0.7 \%\end{array}$ & 2 & 0 & 0 & 0 & 0 & 0 & $\begin{array}{c}2 \\
0.5 \%\end{array}$ \\
\hline Others & $\begin{array}{c}19 \\
6.6 \% \\
\end{array}$ & 9 & 4 & 3 & 1 & 2 & 0 & $\begin{array}{c}40 \\
9.0 \% \\
\end{array}$ \\
\hline Total & 290 & 202 & 50 & 21 & 10 & 5 & 2 & 442 \\
\hline
\end{tabular}

Although initially 10 OMs were included in the study, those of them not employed in at least 15 assessments forms were eliminated; therefore, finally only 6 OMs (Table 2) were taken into consideration in the analysis. As noted above, errors detected by the team were classified into three categories. Each error detected was assigned a code; the first two characters of the code indicate the OM used, the third character indicates the category of error (S: Severe error, M: Moderate error and A: Application error) and the fourth character is a number indicating the order within its category. Appendix 1 presents the list of errors by OM indicating error category, code and description.

No errors were detected in $69.7 \%$ of the reviewed assessments; $13.3 \%$ of the assessments had Severe Errors; 15.2\% had Moderate Errors and 1.8\% had Application Errors (Figure 2). It should be remembered that if a Severe Error was detected in an assessment form, the reviewer coded the assessment as "with severe errors" and did not go on with the analysis process. Table 2 shows the number of errors found in the assessment forms for each OM and error category.

Figure 2. Percentage of assessments with errors and category of error.

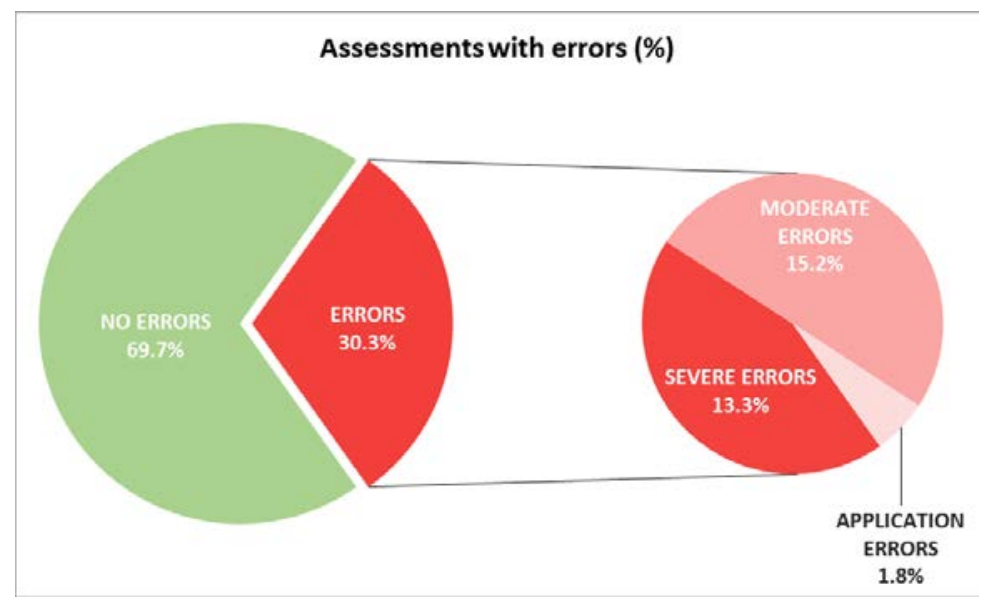


Table 2. Errors and category of error by method

\begin{tabular}{|c|c|c|c|c|c|c|}
\hline \multirow{2}{*}{ Method } & \multirow{2}{*}{$\begin{array}{l}\text { Reviewed } \\
\text { cases }\end{array}$} & \multirow{2}{*}{ Without errors } & \multirow{2}{*}{ With Errors } & \multicolumn{3}{|c|}{ Type of error } \\
\hline & & & & Severe & Moderate & Application \\
\hline RULA & 82 & $\begin{array}{c}60 \\
73.17 \%\end{array}$ & $\begin{array}{c}22 \\
26.83 \%\end{array}$ & $\begin{array}{c}8 \\
9.76 \%\end{array}$ & $\begin{array}{c}13 \\
15.85 \%\end{array}$ & $\begin{array}{c}1 \\
1.22 \%\end{array}$ \\
\hline OWAS & 72 & $\begin{array}{c}63 \\
87.5 \%\end{array}$ & $\begin{array}{c}9 \\
12.5 \%\end{array}$ & $\begin{array}{c}3 \\
4.17 \%\end{array}$ & $\begin{array}{c}4 \\
5.56 \%\end{array}$ & $\begin{array}{c}2 \\
2.78 \%\end{array}$ \\
\hline REBA & 66 & $\begin{array}{c}47 \\
71.21 \%\end{array}$ & $\begin{array}{c}19 \\
28.79 \%\end{array}$ & $\begin{array}{c}4 \\
6.06 \%\end{array}$ & $\begin{array}{c}13 \\
19.70 \%\end{array}$ & $\begin{array}{c}2 \\
3.03 \%\end{array}$ \\
\hline $\mathrm{NIOSH}$ lifting equation & 112 & $\begin{array}{c}65 \\
58.03 \%\end{array}$ & $\begin{array}{c}47 \\
41.96 \%\end{array}$ & $\begin{array}{c}24 \\
21.43 \%\end{array}$ & $\begin{array}{c}22 \\
19.64 \%\end{array}$ & $\begin{array}{c}1 \\
0.89 \%\end{array}$ \\
\hline OCRA Checklist & 62 & $\begin{array}{c}39 \\
62.9 \%\end{array}$ & $\begin{array}{c}23 \\
37.10 \%\end{array}$ & $\begin{array}{c}12 \\
19.35 \%\end{array}$ & $\begin{array}{c}9 \\
14.52 \%\end{array}$ & $\begin{array}{c}2 \\
3.23 \%\end{array}$ \\
\hline BiomechEEC & 48 & $\begin{array}{c}34 \\
70.83 \%\end{array}$ & $\begin{array}{c}14 \\
29.17 \%\end{array}$ & $\begin{array}{c}8 \\
16.67 \%\end{array}$ & $\begin{array}{c}6 \\
12.50 \%\end{array}$ & $\begin{array}{c}0 \\
0 \%\end{array}$ \\
\hline Total & 442 & $\begin{array}{c}308 \\
69.68 \%\end{array}$ & $\begin{array}{c}134 \\
30.32 \%\end{array}$ & $\begin{array}{c}59 \\
13.35 \%\end{array}$ & $\begin{array}{c}67 \\
15.16 \%\end{array}$ & $\begin{array}{c}8 \\
1.81 \%\end{array}$ \\
\hline
\end{tabular}

Table 3 shows what errors (indicated by their error codes) were detected by OM. For a detailed description of the errors see Appendix 1. This table also shows the percentage of assessments by OM and category of error detected. If we consider all the reviewed assessments, the most frequent error occurs when using the NIOSH lifting equation to assess lifting tasks in which the worker carries the load over long distances. A chi-squared test $($ Chi-squared $=22.54, \mathrm{df}=5)$ was performed to compare the observed proportions of assessment with errors by OM, finding that there were significant differences amongst methods ( $p=0.0004$ ) with a confidence level of $95 \%$. An analysis of means with the same confidence level (ANOMS, UDL=0.41, LDL=0.16) showed that the proportion of assessment with errors was significantly lower than average on OWAS (proportion=0.0972) and higher on NIOSH lifting equation (proportion=0.4107). In these analyses, only severe and moderate errors were considered.

Table 3. Class and frequency of errors by method

\begin{tabular}{lllcc}
\hline Method & Class of error & Error code $^{1}$ & Frequency & Percentage \\
\hline RULA & Severe & RU S1 & 4 & $4.88 \%$ \\
& RU S2 & 2 & $2.44 \%$ \\
& RU S3 & 2 & $2.44 \%$ \\
\cline { 3 - 5 } & Moderate & RU M1 & 6 & $7.32 \%$ \\
& RU M2 & 5 & $6.10 \%$ \\
& RU M3 & 2 & $2.44 \%$ \\
\hline
\end{tabular}

\footnotetext{
${ }^{1}$ See Appendix 1 for a detailed description of the errors.
} 


\begin{tabular}{|c|c|c|c|c|}
\hline & Application & $\mathrm{RU} A$ & 1 & $1.22 \%$ \\
\hline \multirow[t]{8}{*}{ REBA } & \multirow{3}{*}{ Severe } & RE S1 & 1 & $1.52 \%$ \\
\hline & & RE S2 & 1 & $1.52 \%$ \\
\hline & & RE S3 & 2 & $3.03 \%$ \\
\hline & \multirow[t]{4}{*}{ Moderate } & RE M1 & 4 & $6.06 \%$ \\
\hline & & RE M2 & 5 & $7.58 \%$ \\
\hline & & RE M3 & 3 & $4.55 \%$ \\
\hline & & RE M4 & 1 & $1.52 \%$ \\
\hline & Application & RE A & 2 & $3.03 \%$ \\
\hline \multirow{12}{*}{$\begin{array}{l}\text { NIOSH lifting } \\
\text { equation }\end{array}$} & \multirow{6}{*}{ Severe } & NI S1 & 4 & $3.57 \%$ \\
\hline & & NI S2 & 8 & $7.14 \%$ \\
\hline & & NI S3 & 2 & $1.79 \%$ \\
\hline & & NI S4 & 4 & $3.57 \%$ \\
\hline & & NI S5 & 2 & $1.79 \%$ \\
\hline & & NI S6 & 4 & $3.57 \%$ \\
\hline & \multirow[t]{5}{*}{ Moderate } & NI M1 & 5 & $4.46 \%$ \\
\hline & & $\mathrm{NI} \mathrm{M} 2$ & 6 & $5.36 \%$ \\
\hline & & NI M3 & 3 & $2.68 \%$ \\
\hline & & $\mathrm{NI}$ M4 & 5 & $4.46 \%$ \\
\hline & & $\mathrm{NI}$ M5 & 3 & $2.68 \%$ \\
\hline & Application & $\mathrm{NI} \mathrm{A}$ & 1 & $0.89 \%$ \\
\hline \multirow[t]{6}{*}{ OWAS } & \multirow{2}{*}{ Severe } & OW S1 & 1 & $1.39 \%$ \\
\hline & & OW S2 & 1 & $1.39 \%$ \\
\hline & \multirow[t]{3}{*}{ Moderate } & OW M1 & 2 & $2.78 \%$ \\
\hline & & OW M2 & 1 & $1.39 \%$ \\
\hline & & OW M3 & 1 & $1.39 \%$ \\
\hline & Application & OW A & 2 & $2.78 \%$ \\
\hline \multirow[t]{9}{*}{ OCRA Checklist } & \multirow{4}{*}{ Severe } & OC S1 & 3 & $4.84 \%$ \\
\hline & & OC S2 & 4 & $6.45 \%$ \\
\hline & & OC S3 & 2 & $3.23 \%$ \\
\hline & & OC S4 & 3 & $4.84 \%$ \\
\hline & \multirow[t]{4}{*}{ Moderate } & OC M1 & 2 & $3.23 \%$ \\
\hline & & OC M2 & 3 & $4.84 \%$ \\
\hline & & OC M3 & 1 & $1.61 \%$ \\
\hline & & $\mathrm{OC} \mathrm{M4}$ & 3 & $4.84 \%$ \\
\hline & Application & $\mathrm{OCA}$ & 2 & $3.23 \%$ \\
\hline \multirow[t]{6}{*}{ BiomechEEC } & \multirow{2}{*}{ Severe } & $\mathrm{BIS1}$ & 5 & $1.42 \%$ \\
\hline & & $\mathrm{BI}$ S2 & 3 & $6.25 \%$ \\
\hline & \multirow[t]{3}{*}{ Moderate } & $\mathrm{BI}$ M1 & 2 & $4.17 \%$ \\
\hline & & $\mathrm{BI}$ M2 & 3 & $6.25 \%$ \\
\hline & & $\mathrm{BI}$ M3 & 1 & $2.08 \%$ \\
\hline & Application & $\mathrm{BI} A$ & 0 & $0 \%$ \\
\hline
\end{tabular}

\section{Discussion}

317 practitioners from 20 different countries took part in this study, being, to the best of our knowledge, the most comprehensive survey about the use of OMs in real practice. The target population in this research were practitioners from companies with more than 10 employees who regularly conduct ergonomics evaluations. Considering an infinite population and a simple random sample, the maximum margin of error is 0,057 at 95\% confidence level. Respondents were selected among the users of a web platform focused on ergonomics assessment methods registered as professionals. Whether these users are representatives of the global population will be discussed later in this section.

The results show that approximately 30\% of the assessments performed by practitioners had errors. In $13 \%$ of the assessments the errors were severe and completely invalidated the results of the evaluation. In $15 \%$ of cases the errors caused an overestimation or underestimation of the MSDs risk in the task under 
assessment. Approximately 2\% of the assessments had errors due to carelessness. The procedure followed in the analysis of errors only took into consideration one Severe Error per assessment although there were more errors. Additionally, the team might not have detected the occurrence of some errors in their analysis of the assessment forms; therefore, the values obtained are lower bounds of the actual percentage of assessments with errors. The conclusion is that at least $30 \%$ of the reviewed assessments had errors of diverse severity.

The demographic and professional profile of the participants (years of experience, age, sex, or country) does not seem to influence the quality of the evaluations performed. It is noteworthy to mention the high number of assessments using the NIOSH lifting equation and OCRA Checklist that contained severe errors (21.45\% and 19.35\%). On the other hand, practitioners commit less severe errors using OWAS (12.5\%). The statistical analysis performed, comparing the observed proportions of assessment with errors by method, found that using the NIOSH lifting equation errors were more likely to be committed. Conversely, the proportion of errors using the OWAS method was significantly lower.

The results of this study are disturbing. Approximately one out of three assessments conducted by practitioners in actual work situations does not adequately assess the level of potential MSDs risk. The assessment of work places plays a central role in preventing or reducing risk factors for musculoskeletal disorders. For practitioners, OMs are the most widely used tools for acquiring relevant and reliable evidence on which to base recommendation for changes to preserve workers' health (David, 2005; Genaidy et al., 1994; Bao et al., 2009). Therefore, the fact that $30 \%$ of the assessments had some kind of error is a matter for serious concern. The efforts of researchers and experts to develop new and improved assessment methods to be used by practitioners in real work environments can be ineffective and useless if these tools are not properly used in practice.

In $28 \%$ of the assessments, the errors found were caused by lack of knowledge or improper use of the OMs (severe and moderate errors). The results suggest that more effort is needed to ensure that practitioners possess better knowledge of OMs and tools used to assess work-related musculoskeletal disorder risks. In many cases, current national regulations do not demand specific qualifications to be in charge of these tasks. Perhaps, stricter laws and regulations relative to the skills and qualification of ergonomics practitioners will be necessary. From the data collected in this survey, it has not been possible 
to find significant correlations between the years of experience in ergonomics assessment and errors committed. Although more research in this regard is still needed, the fact that more experience does not entail fewer errors may suggest that the lack of knowledge about the methods employed does not diminish over time, and that refresher courses would be necessary to improve the results.

The high number of errors detected shows that the analyzed OMs require some ergonomics knowledge and, regrettably, it suggests that practitioners' curricula have not enough ergonomics content to apply them properly. Therefore, practitioners must consider the complexity and the required training level when they select the adequate technique. On the other hand, to perform an assessment correctly a detailed understanding of how the job is done and all the tasks and subtasks involved is needed. It is necessary to ensure that there is agreement on which MSD hazards need to be assessed, the body parts affected, and the tasks or subtasks that should be investigated. Finally, it is necessary to identify the potential risk assessment methods that meet the criteria agreed in the previous steps (OHSCO, 2008). The analyst should select a method based on the reliability, validity, practicality, and purpose of the risk assessment (Takala et al., 2010). The inability of the tools selected by practitioners to adequately represent the assessed tasks may lead to some of the errors observed. As was concluded in Pascual and Naqvi (2008), ergonomic checklists require the least effort by the evaluators and help to gather basic information about a job. Consequently, improved checklists that are more task specific will help practitioners to better identify ergonomics risk, and OM's should only be used if an in-depth risk assessment is really needed.

It is necessary to make some considerations regarding this study. Although there are more accurate and reliable risk assessment techniques, in the present study only OMs were taken into consideration. Although direct measurement or instrument-based methods are more reliable and accurate, and they are usually preferred by researchers, using these techniques implies problems that make its use in real work environments difficult (Li \& Buckle, 1999). OMs appear to be best matched to the needs of practitioners (David, 2005; Genaidy et al., 1994) and hence they are the most widely used in real work situations. On the other hand, there is a wide range of OMs and, therefore, it is very difficult to include all of them in a single study. The OMs initially included in this survey were those most commonly used according to the study by Diego-Mas et al., 2015; however some OMs were eliminated of the present analysis because they were 
received in an insufficient number (at least 15 assessments were required to consider the results as being significant). Finally, six OMs representative of those most commonly used by practitioners were analyzed.

Another limitation of this study is related to the participants in the survey. We obtained responses from 317 practitioners from 20 different countries, however, all of them were Spanish speakers and, with some exceptions, they lived in Spanish speaking countries. Language can be a drawback for self-training and information search. Usually, researchers who develop assessment methods publish their findings in English in scientific journals, and most of technical reports available on the Internet are written in this language. This can be a difficulty for practitioners who do not speak English, since the original information sources are usually in this language. On the other hand, all the professionals who participated in this study employed software for the ergonomics assessments. The use of specific software for the application of OMs helps practitioners to perform calculations and, therefore, it reduces human mistakes. The results would probably differ if assessments were performed without computer aid.

Finally, some standards, such as EN 1005-2 and ISO 11228, have introduced relaxations in the conditions in which some methods can be used. For example, according to EN 1005-2, the NIOSH lifting equation can be used to assess one-handed lifting or lifting carried out by several workers. In the same way, the ISO 11228 standard considers it acceptable to assess lifting tasks carrying the load over a long distance. Therefore, in the context of these standards, errors like NI S2 or NI S4 can be considered acceptable. However, in this study, the original conditions for the applicability of each method has been assumed. Similarly, the biomechanical model used in the BiomechEEC method is intended to assess static strengths. However, in some circumstances (slow movements) this method can be used to evaluate dynamic situations. During the revision of the assessments, applying BiomechEEC in a dynamic task has been considered an error, unless its applicability to that task had been justified.

\section{Conclusions}

The main objective of this study was to determine to what extent the assessment of risk factors for musculoskeletal disorders conducted in companies by practitioners using OMs are performed correctly or, conversely, if the lack of training or experience of professionals could be a cause of errors in the implementation of the assessments. The results show that about $30 \%$ of the analyzed assessments had 
errors. In $13 \%$ of the assessments the errors were severe and completely invalidated the results. In $15 \%$ of cases the errors caused an overestimation or underestimation of the risk in the workplace. Approximately $2 \%$ of the assessments had errors due to carelessness.

The results suggest that a greater effort is needed to ensure that practitioners possess a better knowledge of the techniques used to assess MSD risks, and that the laws and regulations of the different countries should be stricter as regards qualifications and skills required of professionals. On the other hand, practitioners must consider the complexity and the required training level when they select the adequate technique.

\section{Key points}

- 442 risk assessments of actual workplaces carried out by 290 professionals from 20 countries were analyzed to determine their reliability.

- Approximately $30 \%$ of the assessments had errors. $13 \%$ of the errors invalidated the results of the evaluation. $15 \%$ of the errors caused a miss estimation of the risk.

- The results suggest that a greater effort is needed to ensure that practitioners possess a better knowledge of the techniques used to assess risk factors for musculoskeletal disorders.

- Practitioners must consider the complexity, the required training level, and the suitability when they select the adequate technique.

\section{References}

Bao, S., Spielholz, P., Howard, N., \& Silverstein, B. (2009). Force measurement in field ergonomics research and application. International Journal of Industrial Ergonomics, 39(2), 333-340. https://doi.org/10.1016/j.ergon.2008.03.005

Beek, A. van der, \& Frings-Dresen, M. (1998). Assessment of mechanical exposure in ergonomic epidemiology. Occupational Environmental Medicine, 55(5), 291-299. Retrieved from http://oem.bmj.com/content/55/5/291.short

Buckle, P., \& Li, G. (1996). User needs in exposure assessment for musculoskeletal risk assessment. In Proceedings of 1st International Cyberspace Conference on Ergonomics "Cyberg."

Chiasson, M.-È., Imbeau, D., Aubry, K., \& Delisle, A. (2012). Comparing the results of eight methods used to evaluate risk factors associated with musculoskeletal disorders. International Journal of Industrial Ergonomics, 42(5), 478-488. https://doi.org/10.1016/j.ergon.2012.07.003 
Colombini, D., Occhipinti, E., Cairoli, S., \& Barracco, A. (2000). Proposal and preliminary validation of a check-list for the assessment of occupational exposure to repetitive movements of the upper limbs. Medicina Del Lavoro, 102(1), 1-39.

David, G. (2005). Ergonomic methods for assessing exposure to risk factors for work-related musculoskeletal disorders. Occupational Medicine (Oxford, England), 55(3), 190-9. https://doi.org/10.1093/occmed/kqi082

David, G., Woods, V., Li, G., \& Buckle, P. (2008). The development of the Quick Exposure Check (QEC) for assessing exposure to risk factors for work-related musculoskeletal disorders. Applied Ergonomics, 39(1), 57-69. https://doi.org/10.1016/j.apergo.2007.03.002

Diego-Mas, J.-A., Poveda-Bautista, R., \& Garzon-Leal, D.-C. (2015). Influences on the use of observational methods by practitioners when identifying risk factors in physical work. Ergonomics, 58(10), 16601670. https://doi.org/10.1080/00140139.2015.1023851

Genaidy, A. M., Al-Shedi, A. A., \& Karwowski, W. (1994). Postural stress analysis in industry. Applied Ergonomics, 25, 77-87. https://doi.org/10.1016/0003-6870(94)90068-X

Guelaud, F., Beauchesne, M. N., Gautrat, J., \& Roustang, G. (1977). Pour une analyse des conditions du travail ouvrier dans l'entreprise. Aix-en-Provence: Laboratoire d'economie et de sociologie du travail, C.N.R.S.

Hignett, S., \& McAtamney, L. (2000). Rapid entire body assessment (REBA). Applied Ergonomics, 31(2), 201-5. Retrieved from http://www.ncbi.nlm.nih.gov/pubmed/10711982

Karhu, O., Kansi, P., \& Kourinka, I. (1977). Correcting working postures in industry: a practical method for analysis. Applied Ergonomics, 8, 199-201.

Li, G., \& Buckle, P. (1999). Current techniques for assessing physical exposure to work-related musculoskeletal risks, with emphasis on posture-based methods. Ergonomics, 42(5), 674-695. Retrieved from http://www.tandfonline.com/doi/abs/10.1080/001401399185388

Li, G., \& Buckle, P. (2000). Evaluating change in exposure to risk for musculoskeletal disorders - A practical tool. In Proceedings of the XIVth Triennial Congress of the International Ergonomics Association and 44th Annual Meeting of the Human Factors and Ergonomics Association, "Ergonomics for the New Millennnium" (pp. 407-408). Retrieved from http://www.scopus.com/inward/record.url?eid=2-s2.0-

1842708956\&partnerID=40\&md5=6f3390c3f1509a3915d61f18c74448cb

Malchaire, J. (2011). A classification of methods for assessing and / or preventing the risks of musculoskeletal disorders. European Trade Union Institute.

McAtamney, L., \& Corlett, E. N. (1993). RULA: a survey method for the investigation of work-related upper limb disorders. Applied Ergonomics, 24(2), 91-9. Retrieved from http://www.ncbi.nlm.nih.gov/pubmed/15676903

Moore, J. S., \& Garg, A. (1995). The Strain Index: a proposed method to analyze jobs for risk of distal upper extremity disorders. American Industrial Hygiene Association Journal, 56, 443-458. https://doi.org/10.1080/15428119591016863 
Occhipinti, E. (1998). OCRA: a concise index for the assessment of exposure to repetitive movements of the upper limbs. Ergonomics, 41(9), 1290-1311. Retrieved from http://www.tandfonline.com/doi/abs/10.1080/001401398186315

OHSCO. (2008). Musculoskeletal disorders prevention series. Part 3C: MSD prevention toolbox - More on in-depth risk assessment methods. from http://www.iwh.on.ca/system/files/documents/msd_prevention_toolbox_3c_2007.pdf

Pascual, S. A., \& Naqvi, S. (2008). An investigation of ergonomics analysis tools used in industry in the identification of work-related musculoskeletal disorders. International Journal of Occupational Safety and Ergonomics: JOSE, 14(2), 237-45. Retrieved from http://www.ncbi.nlm.nih.gov/pubmed/18534158

Roetenberg, D., Baten, C. T. M., \& Veltink, P. H. (2007). Estimating body segment orientation by applying inertial and magnetic sensing near ferromagnetic materials. IEEE Transactions on Neural Systems and Rehabilitation Engineering, 15(1), 469-471. https://doi.org/10.1109/TNSRE.2007.903946

Snook, S. H., \& Ciriello, V. M. (1991). The design of manual handling tasks: revised tables of maximum acceptable weights and forces. Ergonomics, 34, 1197-1213. https://doi.org/10.1080/00140139108964855

Takala, E.-P., Pehkonen, I., Forsman, M., Hansson, G.-Å., Mathiassen, S. E., Neumann, W. P., ... Winkel, J. (2010). Systematic evaluation of observational methods assessing biomechanical exposures at work. Scandinavian Journal of Work, Environment \& Health, 36(1), 3-24. https://doi.org/10.5271/sjweh.2876

Trask, C., \& Mathiassen, S. (2012). Data collection costs in industrial environments for three occupational posture exposure assessment methods. BMC Medical Research Methodology, 12, 89. Retrieved from http://www.biomedcentral.com/1471-2288/12/89/

Waters, T. R., Putz-Anderson, V., Garg, A., \& Fine, L. J. (1993). Revised NIOSH equation for the design and evaluation of manual lifting tasks. Ergonomics, 36, 749-776. https://doi.org/10.1080/00140139308967940

Wells, R., Norman, R., Neumann, P., \& Andrews, D. (1997). Assessment of physical work load in epidemiologic studies: common measurement metrics for exposure assessment. Ergonomics, 37(6), 979-88. Retrieved from http://www.tandfonline.com/doi/abs/10.1080/001401397188369 


\section{Biographies}

Jose Antonio Diego-Mas is full professor in the Department of Engineering Projects and researcher in the Institute for Research and Innovation in Bioengineering (i3B) of the Universidad Politecnica de Valencia (UPV). He received his PhD in industrial engineering from UPV, Spain, in 2006.

Rocio Poveda-Bautista is full professor in the Department of Engineering Projects and researcher in INGENIO, a joint research institute of the Spanish National Research Council (CSIC) and the UPV. She received her PhD in industrial engineering from UPV, Spain, in 2007.

Jorge Alcaide-Marzal is full professor in the Department of Engineering Projects and researcher in the Institute for Research and Innovation in Bioengineering (i3B) of the UPV. He received his $\mathrm{PhD}$ in industrial engineering from UPV, Spain, in 2004. 


\section{Appendix 1. Errors}

Errors detected in the use of the RULA method (error class and description).

\begin{tabular}{|c|c|c|}
\hline $\begin{array}{l}\text { Class of } \\
\text { error }\end{array}$ & $\begin{array}{l}\text { Error } \\
\text { Code }\end{array}$ & Description \\
\hline \multirow{3}{*}{$\begin{array}{l}\text { Severe } \\
\text { Errors }\end{array}$} & RU S1 & Using the method for assessing a risk factor for which it was not designed. \\
\hline & $\mathrm{RU} \mathrm{S} 2$ & $\begin{array}{l}\text { Using together data of both sides of the body (RULA evaluates a single body side: left or } \\
\text { right). }\end{array}$ \\
\hline & RU S3 & Using data from various body postures (RULA evaluates only one posture). \\
\hline \multirow{3}{*}{$\begin{array}{l}\text { Moderate } \\
\text { Errors }\end{array}$} & RU M1 & $\begin{array}{l}\text { Incorrect measurement of angles between body members due to misusing the references } \\
\text { defined by the method (e.g. bending angle of the trunk measured from a reference other } \\
\text { than the vertical axis). }\end{array}$ \\
\hline & $\mathrm{RU} M 2$ & $\begin{array}{l}\text { Angle measurements on photographs of workers which do not clearly show the angles } \\
\text { between the members of the body, or when the angles are showed in inadequate } \\
\text { perspective. }\end{array}$ \\
\hline & RU M3 & $\begin{array}{l}\text { Errors in coding body postures, sustained loads or type of muscular activity. (e.g. not } \\
\text { considering that if the forearm crosses the center line of the body the forearm score should } \\
\text { be increased by one point). }\end{array}$ \\
\hline $\begin{array}{l}\text { Application } \\
\text { errors }\end{array}$ & RU A & $\begin{array}{l}\text { Errors in the use of software, incorrect calculations, errors when changing measurement } \\
\text { units... }\end{array}$ \\
\hline
\end{tabular}

Errors detected in the use of the REBA method (error type and description).

\begin{tabular}{ccl}
$\begin{array}{c}\text { Class of } \\
\text { error }\end{array}$ & Error Code & \\
\hline $\begin{array}{c}\text { Severe } \\
\text { Errors }\end{array}$ & RE S1 & $\begin{array}{l}\text { Using the method for assessing a risk factor for which it was not designed. } \\
\text { Using together data of both sides of the body (REBA evaluates a single body side: left } \\
\text { or right). } \\
\text { Using data from various body postures (REBA evaluates only one posture). }\end{array}$ \\
\hline $\begin{array}{c}\text { Moderate } \\
\text { Errors }\end{array}$ & RE S3 & $\begin{array}{l}\text { Incorrect measurement of angles between body members due to misusing the } \\
\text { references defined by the method. } \\
\text { Angle measurements on photographs of workers which do not clearly show the angles } \\
\text { between the members of the body, or when the angles are showed in inadequate } \\
\text { perspective. } \\
\text { Errors in coding body postures, sustained loads or type of muscular activity. } \\
\text { Risapplication of the Gravity Assisted condition. }\end{array}$ \\
\hline $\begin{array}{c}\text { Application } \\
\text { errors }\end{array}$ & RE A & $\begin{array}{l}\text { Errors in the use of software, incorrect calculations, errors when changing measurement } \\
\text { units... }\end{array}$ \\
\hline
\end{tabular}


Errors detected in the use of the NIOSH Lifting Equation method (error class and description).

\begin{tabular}{|c|c|c|}
\hline Class of error & $\begin{array}{l}\text { Error } \\
\text { Code }\end{array}$ & Description \\
\hline \multirow{6}{*}{$\begin{array}{c}\text { Severe } \\
\text { Errors }\end{array}$} & NI S1 & Using the method for assessing a risk factor for which it was not designed. \\
\hline & $\mathrm{NIS} 2^{*}$ & $\begin{array}{l}\text { Carrying a load over a long distance or heavy load pulling or pushing when these } \\
\text { activities are important in respect to the assessed load lifting (the equation should only } \\
\text { be used if the activity that accompanies load lifting is no more than } 10 \% \text { of the worker's } \\
\text { activity). }\end{array}$ \\
\hline & NI S3 & Prolonged sitting or kneeling periods. \\
\hline & NI S4* & Manual handling operations with one hand or by several workers. \\
\hline & NI S5 & $\begin{array}{l}\text { Multi-task analysis of non-alternating tasks (multitasking analysis applies when load- } \\
\text { lifting conditions vary and are performed alternately. e.g. different heights or different } \\
\text { load weights). }\end{array}$ \\
\hline & NI S6 & Analyzing several simple tasks as multitasking load lifting. \\
\hline \multirow{5}{*}{$\begin{array}{c}\text { Moderate } \\
\text { Errors }\end{array}$} & NI M1 & $\begin{array}{l}\text { Other unfulfilled conditions relative to the use of the method (e.g. the knee flexion is } \\
\text { greater than } 15^{\circ} \text { when lifting a load, the load is unstable, or with unstable center of } \\
\text { gravity). }\end{array}$ \\
\hline & $\mathrm{NI}$ M2 & $\begin{array}{l}\text { Erroneous measurements of distances or angles (e.g. incorrect measurement of the } \\
\text { asymmetry angle due to using wrong reference points). }\end{array}$ \\
\hline & NI M3 & $\begin{array}{l}\text { Not considering significant load control at the destination point (if there is significant } \\
\text { load control at the end of the lifting, the task should be assessed both at the beginning } \\
\text { and end of the movement by applying the NIOSH equation twice). }\end{array}$ \\
\hline & NI M4 & $\begin{array}{l}\text { Misinterpretation of body recovery times (e.g. to calculate the Frequency Multiplier the } \\
\text { period of time the worker is engaged in other tasks not involving load handling should } \\
\text { be considered). }\end{array}$ \\
\hline & NI M5 & $\begin{array}{l}\text { Misinterpretation of the coupling or quality of the workers grip on the object (error in } \\
\text { determining the value of the Coupling Multiplier depending on whether the load has a } \\
\text { gripping system, the position of the fingers of the worker or the volume and shape of } \\
\text { the object). }\end{array}$ \\
\hline $\begin{array}{l}\text { Application } \\
\text { errors }\end{array}$ & $\mathrm{NI} A$ & $\begin{array}{l}\text { Errors in the use of software, which are not due to errors in the selection or application } \\
\text { of the method, errors when changing measurement units... }\end{array}$ \\
\hline
\end{tabular}

$(*)$ The standards EN 1005-2 and ISO 11228 have introduced some relaxations in the conditions in which NIOSH Lifting Equation can be applied. In the context of these standards, tasks in which the load is carried a long distance or handled with one hand are suitable for this method under some conditions. In this work, practitioners used the NIOSH equation out of the context of EN 1005-2 and ISO 11228 standards. Therefore, NI S2 and NI S4 have been considered severe errors.

Errors detected in the use of the OWAS method (error class and description).

\begin{tabular}{ccl}
\hline Class of error & $\begin{array}{c}\text { Error } \\
\text { Code }\end{array}$ & \multicolumn{1}{c}{ Description } \\
\hline $\begin{array}{c}\text { Severe } \\
\text { Errors }\end{array}$ & OW S1 & $\begin{array}{l}\text { Using the method for assessing a risk factor for which it was not designed. } \\
\text { Inadequate sampling frequency (very infrequent, irregular ...). In a sample of 100 } \\
\text { observations the estimated error is about 10\%, whereas for } 400 \text { observations the error } \\
\text { decreases to about half (5\%). }\end{array}$ \\
\hline $\begin{array}{c}\text { Moderate } \\
\text { Errors }\end{array}$ & OW M2 & $\begin{array}{l}\text { Miscoding of body postures or sustained loads from observations. } \\
\text { Worker's body and the correct coding of body postures. } \\
\text { Misinterpretation of the health risk categories from the relative frequencies of each } \\
\text { body posture. }\end{array}$ \\
\hline $\begin{array}{c}\text { Application } \\
\text { errors }\end{array}$ & OW A & $\begin{array}{l}\text { Errors in the use of software, errors due to incorrect calculations, errors when } \\
\text { changing measurement units... }\end{array}$ \\
\hline
\end{tabular}


Errors detected in the use of the OCRA Check List method (error class and description).

\begin{tabular}{|c|c|c|}
\hline Class of error & $\begin{array}{l}\text { Error } \\
\text { Code }\end{array}$ & Description \\
\hline \multirow{4}{*}{ Severe errors } & OC S1 & Using the method for assessing a risk factor for which it was not designed. \\
\hline & OC S2 & $\begin{array}{l}\text { Incorrect calculation of breaks and non-repetitive tasks in calculating the net time of } \\
\text { repetitive work. }\end{array}$ \\
\hline & OC S3 & $\begin{array}{l}\text { Using mixed-up data from both sides of the body (posture Factor must be calculated } \\
\text { with data from one side of the body, left or right). }\end{array}$ \\
\hline & OC S4 & $\begin{array}{l}\text { Assessments in which the worker performs several tasks as if it were a unique task } \\
\text { (when the worker performs several tasks, the risks of each individual task weighted } \\
\text { based on the time the worker spends in performing each task must be analyzed). }\end{array}$ \\
\hline \multirow{4}{*}{$\begin{array}{l}\text { Moderate } \\
\text { errors }\end{array}$} & OC M1 & $\begin{array}{l}\text { Incorrect calculation of recovery periods (e.g. the time spent on non-repetitive tasks } \\
\text { should be considered as recovery period). }\end{array}$ \\
\hline & $\mathrm{OC} \mathrm{M} 2$ & $\begin{array}{l}\text { Errors in Technical Actions performed in the task (a Technical Action is a movement or } \\
\text { movements necessary to complete a simple operation, e.g. moving, reaching, grasping } \\
\text { an object with the hand or fingers, etc.). }\end{array}$ \\
\hline & OC M3 & $\begin{array}{l}\text { Do not consider additional risk factors: exposure to cold, wearing gloves, injuries from } \\
\text { tool operation, vibrations ... }\end{array}$ \\
\hline & OC M4 & $\begin{array}{l}\text { Errors in the calculation of the cycle time (mainly by using the number of pieces } \\
\text { produced to estimate the total number of cycles when several pieces are produced per } \\
\text { cycle). }\end{array}$ \\
\hline $\begin{array}{l}\text { Application } \\
\text { errors }\end{array}$ & OC A & $\begin{array}{l}\text { Errors in the use of software, errors due to incorrect calculations, errors when } \\
\text { changing measurement units... }\end{array}$ \\
\hline
\end{tabular}

Errors detected in the use of the BiomechEEC method (error class and description).

\begin{tabular}{ccl}
\hline Class of error & $\begin{array}{c}\text { Error } \\
\text { Code }\end{array}$ & \multicolumn{1}{c}{ Description } \\
\hline Severe errors & BI S1 & $\begin{array}{l}\text { Non-static effort (the posture of the worker must be static, the model used by the } \\
\text { method does not consider load inertia or significant accelerations). } \\
\text { Non-coplanar effort (the model used by the method does not consider torques in the } \\
\text { sagittal plane of the worker). }\end{array}$ \\
\hline $\begin{array}{c}\text { Moderate } \\
\text { errors }\end{array}$ & BI M2 & $\begin{array}{l}\text { Load generates torques in the body (the model used by the method considers that the } \\
\text { load should not generate torques in the body). } \\
\text { Body parts included in the analysis lie on an object (the model considers that only the } \\
\text { feet should be in contact with the ground). } \\
\text { Inaccurate measurement of the anthropometric dimensions (the human model } \\
\text { employed by the method consists of 16 segments). }\end{array}$ \\
\hline $\begin{array}{c}\text { Application } \\
\text { errors }\end{array}$ & BI A & $\begin{array}{l}\text { Errors in the use of software, errors due to incorrect calculations, errors when } \\
\text { changing measurement units... }\end{array}$ \\
\hline
\end{tabular}

